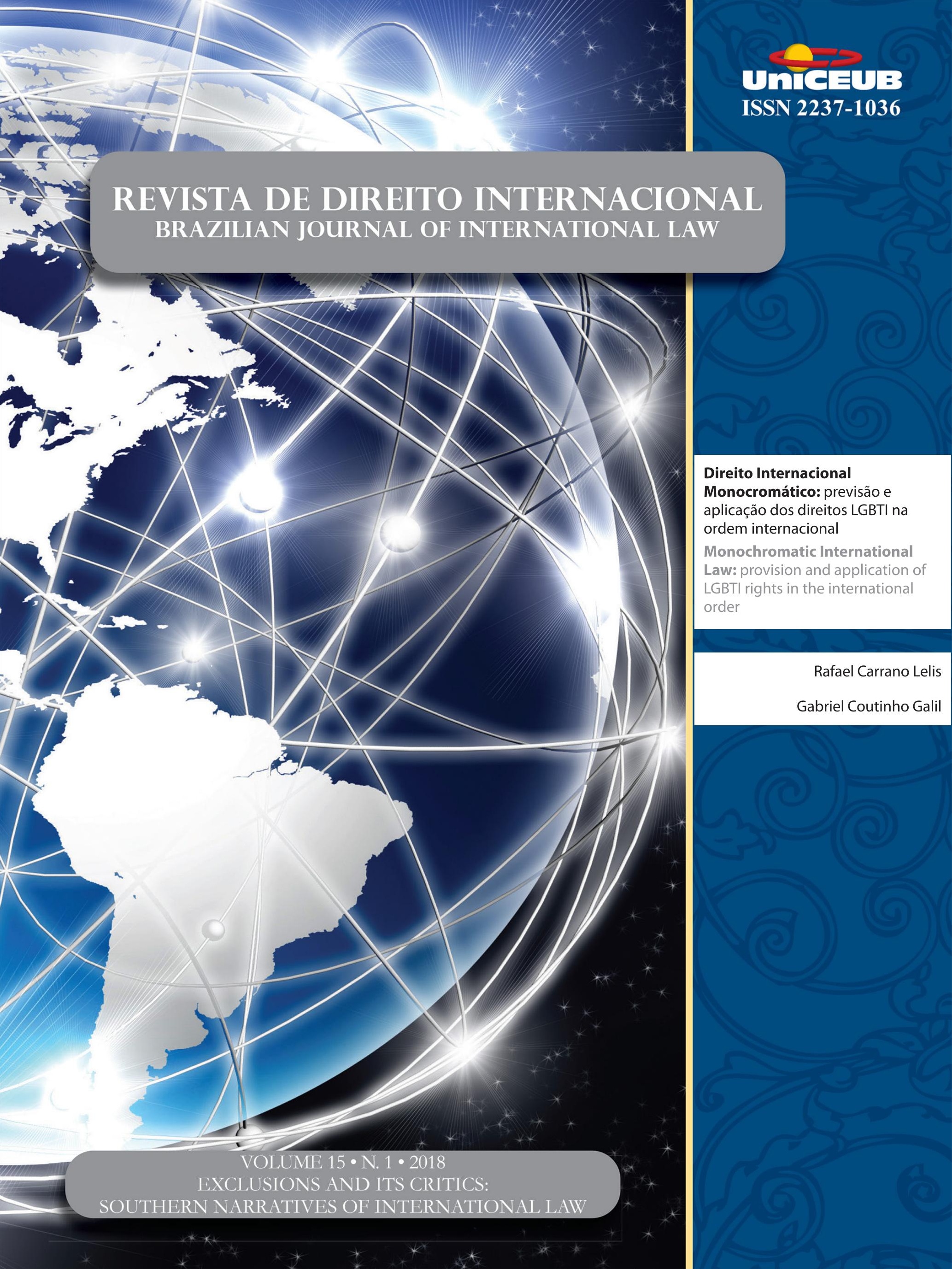




\section{Sumário}

I. Dossiê Especial: Exclusions and its Critics: Southern Narratives of

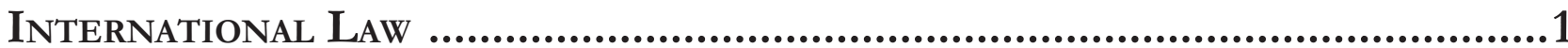

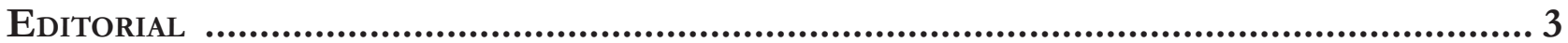

Conseguimos pensar em narrativas críticas do Direito Internacional no Sul Global? ......................... 3

ENTRE A APOLOGIA E A UTOPIA: A POLÍTICA Do DIREITO INTERNACIONAL................................ 6 Martti Koskenniemi e Tradutor João Roriz

A POLÍTICA Do DIREITO INTERNACIONAL: 20 ANOS DEPOIS ...................................................31 Martti Koskenniemi e Tradutor João Roriz

Abordagens terceiro-mundistas para o Direito Internacional: Um Manifesto............42 Bhupinder S. Chimni

Around the pyramid: Political-theoretical challenges to law in the age of global GOVERNANCE

Salem Hikmat Nasser e José Garcez Ghirardi

VOICE AND EXIT: HOW EMERGING POWERS ARE PROMOTING INSTITUTIONAL CHANGES IN THE INTERNATIONAL MONETARY SYSTEM

Camila Villard Duran

LA LIBRE AUTODETERMINACIÓN DE LOS PUEBLOS EN EL SIGLO XXI: UNA APROXIMACIÓN DE LA HISTORIA DEL COLONIALISMO Y EL NEO-COLONIALISMO DESDE LOS PUEBLOS DEL TERCER MUNDO

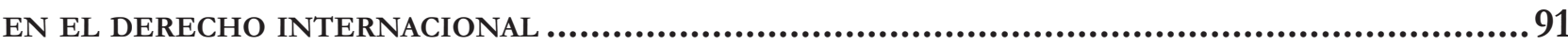

Germán Medardo Sandoval Trigo

INTERNATIONAL CLIMATE CHANGE REGIME AS A PROMOTER OF COLONIAL SYSTEMIC AND SYMBOLIC VIOLENCE: ITS RELATIONSHIP WITH INTERNATIONAL ENVIRONMENT SECURITY AND FOOD SYSTEM THRU THE LENS OF FEMINIST APPROACH 106

Douglas Castro e Bruno Pegorari 
Jus COGENS: AN EUROPEAN CONCEPT? AN EMANCIPATORY CONCEPTUAL REVIEW FROM THE INTER-AMERICAN SYSTEM OF HUMAN RIGHTS

Tatiana de A. F. R. Cardoso Squeff e Marina de Almeida Rosa

O CONHECIMENTO TRADICIONAL RELACIONADO AO COMPLEXO DO CURARE E A LEGISLAÇÃO IN-

TERNACIONAL SOBRE PROPRIEDADE INTELECTUAL. 139

Marcos Vinício Chein Feres e João Vitor de Freitas Moreira

II. Artigos sobre outros temas

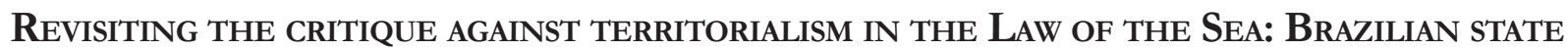
PRACTICE IN LIGHT OF THE CONCEPTS OF CREEPING JURISDICTION AND SPOLIATIVE JURISDICTION ..161 Victor Alencar Mayer Feitosa Ventura

EDUCAÇÃO SUPERIOR INTERCULTURAL, RECONHECIMENTO E REDISTRIBUIÇÃO: O DURO CAMINHO DOS POVOS INDÍGENAS NO EQUADOR 180

Vanessa Wendhausen Cavallazzi, Patrícia Perrone Campos Mello e Raony Soares

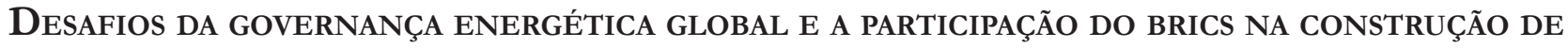
UM NOVO PARADIGMA ENERGÉTICO 200

Fernanda Volpon e Marilda Rosado de Sá Ribeiro

A hermeneutical analysis on the recognition of China as a market economy after 2016.

Alberto Amaral Júnior e Aline Pereira de Carvalho Heringer

THE ISIS ERADICATION OF CHRISTIANS AND YAZIDIS: HUMAN TRAFFICKING, GENOCIDE, AND THE MISSING INTERNATIONAL EFFORTS TO STOP IT

Sarah Myers Raben

The strategic prudence of The Inter-American Court of Human Rights: Rejection OF REQUESTS FOR AN ADVISORY OPINION 255

Cecilia M. Bailliet

Direito Internacional Monocromático: PREVISÃo e apliCaÇÃo dos Direitos LGBTI NA ORDEM INTERNACIONAL 278

Rafael Carrano Lelis e Gabriel Coutinho Galil 
III. RESENHAS

Resenha do livro Empire de Michael Hardt e Antonio Negri 301 Arthur Roberto Capella Giannattasio

Resenha do livro Imperialism, Sovereignty and the Making of International LaW, de

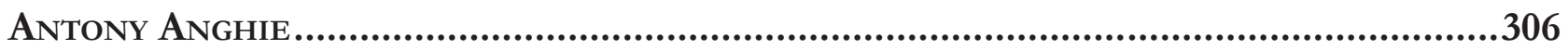

Fabrício José Rodrigues de Lemos e Laura Madrid Sartoretto 


\title{
Direito Internacional Monocromático: previsão e aplicação dos direitos LGBTI na ordem internacional*
}

\section{Monochromatic International Law: provision and application of LGBTI rights in the international order}

\author{
Rafael Carrano Lelis** \\ Gabriel Coutinho Galil ${ }^{* * *}$
}

\section{Resumo}

O trabalho investiga a abrangência da proteção conferida pelas normas de direito internacional às pessoas LGBTIs. Sob o marco teórico do reconhecimento enquanto status social, proposto por Nancy Fraser, questiona-se se o direito internacional fornece proteção e reconhecimento suficientes aos LGBTIs, utilizando-se o método jurídico-compreensivo de investigação e as técnicas de revisão bibliográfica, análise documental e pesquisa jurisprudencial. Os resultados obtidos revelam a ausência de direitos aos LGBTIs em documentos internacionais vinculantes, bem como uma jurisprudência que garante direitos a esses indivíduos majoritariamente sob o fundamento do direito à privacidade. Concluiu-se, portanto, pela existência de um paradigma que se chamou de Direito Internacional Monocrático, isto é, que não fornece reconhecimento ou proteção suficientes aos LGBTIs, invisibilizando-os.

Palavras-chave: LGBTI; Direito Internacional Monocromático; Cortes Internacionais de Direitos Humanos.

\section{Abstract}

The paper investigates the extent of the protection to LGBTI people under international law norms. Guided by the theoretical framework of recognition as a matter of social status, proposed by Nancy Fraser, it is questioned whether international law provides sufficient protection and recognition to LGBTI by using the juridical-comprehensive method of investigation and the techniques of literature review, documental analysis and case-law resear$\mathrm{ch}$. The results indicate an absence of LGBTI rights in international binding documents, as well as precedents that recognize rights to these individuals mainly under the fundament of the right to privacy. It can be concluded, therefore, that exists a paradigm of the Monochromatic International Law which doesn't provide sufficient recognition nor protection to LGBTI people and also invisibilizes them.

Keywords: LGBTI; Monochromatic International Law; International Courts of Human Rights. 


\section{INTRODUÇÃO}

Lésbicas, gays, bissexuais, trans e intersex $\left(\mathrm{LGBTI}^{1}\right)$ têm sua mera existência criminalizada em, pelo menos, 72 países. Além disso, mesmo quando a discriminação contra essas pessoas não é imposta pela legislação, ela se dá de forma efetiva, física e simbolicamente, pela população de cada país, ocasionando a morte de milhares LGBTIs todos os anos. A esfera de preocupação desses indivíduos inclui onde podem ou não dar as mãos, onde podem ou não expressar sua identidade de gênero livremente, onde precisam ou não temer simplesmente andar pelas ruas. É negada a esses indivíduos a mínima dignidade inerente à pessoa humana e seu próprio reconhecimento enquanto sujeitos de direitos.

É com base nessa violência sofrida pelos LGBTIs em todo o mundo e seu não reconhecimento como sujeitos de direitos que se justifica este trabalho. Dessa forma, sustentando-se no marco teórico do reconhecimento enquanto uma questão de status social, proposto por Nancy Fraser, segundo o qual a legislação e a jurisprudência possuiriam um importante papel na mitigação das desigualdades, indagou-se se o Direito Internacional fornece proteção e reconhecimento suficientes aos LGBTIs.

O Direito Internacional é importante precursor da proteção e garantia de direitos a minorias representativas. É justamente nesse plano que se vê avançar a concretização dos Direitos Humanos, na tentativa de estabelecer padrões mínimos de existência a cada indivíduo da sociedade. Em um contexto no qual os LGBTIs possuem uma quantidade inimaginável de direitos negados e não reconhecidos, a análise da tutela dos direitos dessa população na esfera internacional é importante para uma real compreensão da importância que é dada eles. Entende-se, assim, que o plano internacional representa o cenário no qual a tutela dos Direitos Humanos ocorre de forma mais abrangente, permitindo evidenciar o quão perto (ou longe) se está de se assegurar uma vida

1 A utilização da sigla "LGBTI" não tem a intenção de excluir quaisquer outras formas de identidade ou sexualidade que não sejam diretamente abarcadas por suas letras. Definiu-se sua utilização, justamente, por se considerar uma das formas mais inclusivas de menção aos diversos indivíduos dessa população. Ademais, em coerência com o marco teórico adotado, entende-se estar mais próximo de um remédio transformador, como será visto adiante, ao se utilizar uma sigla com um menor número de letras e que, ainda sim, represente uma grande diversidade de indivíduos, como ao se utilizar a letra " $T$ " para se referir às diversas integrantes da população trans. digna aos LGBTIs.

Para além dessa primeira razão, podem ser destacados dois motivos para a escolha do plano internacional: a alteração do próprio espaço de realização da justiça, como proposto por $\mathrm{Fraser}^{2}$, sendo transposto para além das meras fronteiras dos Estados, adquirindo proeminência a dimensão global de efetivação dos direitos; e a influência exercida pelo Direito Internacional no campo jurídico doméstico.

Com a intensificação da globalização, os Estados, com suas limitações fronteiriças, não são mais capazes de dirimir, isoladamente, as desigualdades ocasionadas em virtude das dimensões econômica, cultural e política da justiça. Dessa forma, transporta-se o protagonismo de promoção da justiça dos Estados para a esfera internacional, mais apropriada a suprir as diversas demandas advindas de um mundo mais integrado e cosmopolita ${ }^{3}$. Nesse ponto, é essencial o papel exercido pelos sistemas internacionais, regionais e global, de proteção dos Direitos Humanos; pelos tratados multilaterais e demais fontes de Direito Internacional; bem como pela atuação da sociedade civil transnacional e organizações internacionais, atores cruciais na efetivação da justiça na contemporaneidade.

Tal análise é embasamento suficiente para a expansão da luta por direitos LGBTIs para o plano internacional. Além disso, levando-se em consideração um processo contínuo de desenvolvimento normativo no Direito Internacional, é possível sinalizar o forte peso transformador dos tratados internacionais, gerando alterações na legislação interna de cada país ${ }^{4}$. Dessa maneira, adotando-se a concepção de um sistema de proteção multinível para a efetiva tutela dos direitos LGBTIs,

2 FRASER, Nancy. Reenquadrando a Justiça em um Mundo Globalizado. Lua Nova, São Paulo, n. 77, p. 11-39, 2009, p. 29-32.

3 FRASER, Nancy. Reenquadrando a Justiça em um Mundo Globalizado. Lua Nova, São Paulo, n. 77, 2009, p. 11-17.

4 Apesar de o trabalho ter como foco a proteção oferecida às pessoas LGBTIs a partir do Direito Internacional Público, não se ignora a proteção oferecida à pessoa humana a partir do Direito Internacional Privado, sendo ela, em alguns casos, como no do reconhecimento da união homoafetiva, até mesmo anterior àquela oferecida pelo Direito Internacional Público, $c f$. VASCONCELOS, Raphael Carvalho de. Constituicionalização e Direito Internacional Privado no Brasil. Rev. secr. Trib. perm. revis. ano 4, mai. 2016, p 192. Ainda, sobre o importante papel da disciplina na temática LGBTI $c$. ALMEIDA, Bruno Rodrigues de. Os casamentos e as parcerias entre pessoas do mesmo sexo no direito internacional privado brasileiro: aspectos transnacionais das famílias contemporâneas. Revista de Direito Internacional, Brasília, v. 11, n. 1, 2014 p. 43-52. 
é essencial o avanço normativo no plano internacional. Sob tal perspectiva, faz-se necessária a construção de uma proteção a nível local, regional e global. Nesse sentido, os organismos internacionais detêm forte "impacto transformador", desencadeando o avanço na proteção dos Direitos Humanos no ordenamento jurídico interno de cada país ${ }^{5}$.

Como suposição inicial para responder ao questionamento da pesquisa, adotou-se a hipótese de que o Direito Internacional não fornece o reconhecimento e proteção necessários aos LGBTIs, atuando de maneira tímida na defesa de seus direitos e contribuindo para sua constante invisibilização. Nesse ponto, é importante conceituar o que denominamos de "Direito Internacional Monocromático". Como poder ser aduzido, faz-se tal referência em razão da invisibilidade sofrida pelos LGBTIs no Direito Internacional, fazendo com que essa dimensão do direito abarque apenas "uma cor", excluindo uma pluralidade de sujeitos, quais sejam, a própria população LGBTI, cuja diversidade é comumente simbolizada pelas várias cores do arco-íris. Esse conceito se traduziria, de forma normativa, na ausência de legislação que trate expressamente de pessoas LGBTIs, garantindo sua proteção e reconhecimento. E, ainda, em uma jurisprudência que se apoie em fundamentos demasiadamente genéricos, possibilitando grande variação na esfera de proteção desses indivíduos.

Sendo assim, a partir de um raciocínio hipotético-dedutivo, o problema levantado foi abordado pela utilização do método jurídico-compreensivo de investigação, que privilegia a decomposição do problema jurídico sob diversos aspectos para sua total compreensão. Desse modo, foram empregadas as técnicas de pesquisa de revisão bibliográfica, investigação documental e pesquisa jurisprudencial para a obtenção e exame de dados primários e secundários, visando à construção de uma pesquisa empírica de caráter tanto quantitativo, quanto qualitativo.

A revisão bibliográfica permitiu a definição e aprofundamento do marco teórico adotado, por meio da leitura das diversas críticas levantas à concepção de reconhecimento elaborada por Nancy Fraser. Além disso, auxiliou no levantamento de dados secundários

5 PIOVESAN, Flávia. Sistema Interamericano de Direitos Humanos: impacto transformador, diálogos jurisdicionais e os desafios da reforma. Revista de Estudos Constitucionais, Hermenêutica e Teoria do Direito, 6(2), jul-set 2014, p. 143-144. referentes ao atual estágio de proteção e tratamento dos direitos LGBTIs no cenário global. A investigação documental, por sua vez, possibilitou a coleta de dados primários referentes à positivação dos direitos LGBTIs na ordem internacional, seja em tratados, resoluções da Organização das Nações Unidas ou princípios orientadores. Por fim, a técnica de pesquisa jurisprudencial, a partir da seleção de uma amostragem não probabilística, oportunizou o levantamento de dados primários para a análise do tratamento judicial dado aos direitos LGBTIs pelas Cortes de Direitos Humanos.

O objetivo geral da pesquisa é demonstrar a invisibilização sofrida pelos LGBTIs no Direito Internacional dos Direitos Humanos, seja na legislação, seja na jurisprudência. Como objetivos específicos desta investigação podem ser evidenciados: realizar revisão bibliográfica sobre a temática; analisar as normas de Direito Internacional quanto ao grau de proteção conferido aos LGBTIs; evidenciar todas as normativas de Direito Internacional que abordem os direitos das pessoas LGBTIs; analisar a jurisprudência das Cortes de Direitos Humanos relativas à temática; indicar a necessidade de mudança de paradigma no tratamento dado pelo Direito Internacional às pessoas LGBTIs com o protagonismo dos indivíduos afetados (bottom up).

\section{O DIREITO INTERNACIONAL COMO FONTE DE RECONHECIMENTO}

Os estudos da filósofa estadunidense Nancy Fraser marcaram, de forma singular, o pensamento no campo da teoria da justiça. Por meio de um processo dialético e constante de reanálise de suas ideias, Fraser $^{6}$ concebeu uma teoria da justiça tridimensional. Dessa forma, visando à concretização da justiça, três dimensões centrais devem ser observadas: a econômica, que se concretiza por meio da distribuição; a cultural, que comporta a ideia de reconhecimento; e a política, materializada pela representação. A partir disso, extrai-se que as formas pelas quais a injustiça se consubstancia são a má distribuição, o falso reconhecimento e a falsa representação. Como previamente mencionado, interessa especialmente ao desenvolvimento do trabalho uma análise mais aprofundada das consequências advindas do falso reconhe-

6 FRASER, Nancy. Reenquadrando a Justiça em um Mundo Globalizado. Lua Nova, São Paulo, n. 77, 2009, p. 17-18. 
cimento, motivo pelo qual tal dimensão será abordada com maior enfoque.

Em um primeiro momento, é imprescindível que se destaque a importância e autonomia do reconhecimento na teoria fraseriana. Fraser ${ }^{7}$ rechaça a ideia de que a opressão aos LGBTIs seria "meramente cultural"8 e assevera que o falso reconhecimento ocorre de forma institucionalizada nos espaços sociais. A desigualdade do falso reconhecimento possui materialidade em si mesma, não podendo ser reduzida ou subordinada à ideia de má distribuição, ainda que, em algum momento, elas possam se dar conjuntamente.

Marco teórico do artigo, a teoria do reconhecimento enquanto uma questão de status social contrasta diretamente com o modelo identitário hegeliano, segundo o qual o reconhecimento seria uma relação recíproca em que os sujeitos se veem como iguais, mesmo que de forma separada ${ }^{9}$. Portanto, em nossa concepção, não ser reconhecido significa ser socialmente subordinado. Isto é, o indivíduo que sofre da injustiça do falso reconhecimento é institucionalmente invisibilizado, classificado como abjeto e impedido de participar da vida de forma paritária com os demais ${ }^{10}$. Desse modo, ainda que diretamente conectado à má distribuição e à falsa representação, o falso reconhecimento se materializa de forma independente, afetando, profundamente, a existência daqueles que sofrem a desigualdade nessa dimensão, tornando-os suscetíveis a múltiplas e distintas formas de violência, discriminação e exclusão.

Fraser ${ }^{11}$ utiliza a população LGBTI como um exem-

7 FRASER, Nancy. Heterosexism, Misrecognition, and Capitalism: A Response to Judith Butler. Social Text, Durham, v. 0, n. 52/53, p. 279-289, 1997 , p. 279-280.

8 A expressão "meramente cultural" é utilizada por Butler para tecer críticas à teoria fraseriana que, segundo sua interpretação, desclassificaria a opressão sofrida por pessoas LGBTIs à esfera cultural, ignorando a materialidade dessa opressão, assim como sua centralidade no funcionamento econômico, a partir do sistema sexogênero-desejo, sendo indissociável da esfera da distribuição (Butler, Judith. Meramente Cultural. Revista Idéias, Campinas, SP. Vol. 7. $\mathrm{n}^{\circ} 2$. pp. 227-244). No entanto, em produção posterior, Fraser reafirma a indissociabilidade das esferas econômica, cultural e política, sendo esta a concepção adotada pelo presente trabalho.( FRASER, Nancy. Heterosexism, Misrecognition, and Capitalism: A Response to Judith Butler. Social Text, Durham, v. 0, n. 52/53, p. 279-289, 1997.)

9 FRASER, Nancy. Rethinking Recognition. New Left Review, Londres, n. 3, maio-jun 2000, p. 109.

10 FRASER, Nancy. Rethinking Recognition. New Left Review, Londres, n. 3, maio-jun 2000, p. 113-114.

11 FRASER, Nancy. From Redistribution to Recognition? Dilem- plo de coletividade cuja opressão estaria enraizada, majoritariamente, na esfera cultural e, portanto, no âmbito do reconhecimento. Não obstante reconheça que essa população sofra injustiça ligada à dimensão econômica e política, o aspecto cultural predomina com relação a esses indivíduos, tornando-os formas de identidades e sexualidades desprezadas. Caracteriza, assim, o heterossexismo e a homofobia como, respectivamente, a edição de normas que arbitrariamente privilegiam a heterossexualidade e uma forma cultural de menosprezo da homossexualidade. $^{12}$

Como solução, a autora apresenta duas alternativas de remédios: os afirmativos e os transformativos. O afirmativo seria aquele que busca solucionar a falta de reconhecimento da população LGBTI a partir de ações ligadas à identidade desse grupo, buscando diferenciá-los para que possam receber um tratamento mais igualitário na sociedade, como poderia se dar a partir de políticas de cotas, programas de inclusão da população no mercado de trabalho e, até mesmo, das organizações das marchas de orgulho LGBTI. Por outro lado, um remédio transformativo é substancialmente mais alinhado aos pensamentos da Teoria Queer, buscando eliminar a dicotomia binária entre homo e heterossexual, masculino e feminino, cis e trans. ${ }^{13}$ Os dois remédios propostos possuem, em diferentes graus, a função de promover a justiça para essa população. Todavia, enquanto o remédio transformativo parece, em longo prazo, oferecer um cenário ideal para que essa população se livre de todas as formas de injustiças e opressões, o afirmativo oferece soluções mais imediatas e que exigem reestruturações menos drásticas aos atuais arranjos sociais, podendo se materializar por meio de uma legislação fortemente protetiva que, ao mesmo tempo, reconheça direitos substantivos e proíba a discriminação a essa população.

O Direito, seja pela legislação, seja pela jurisprudência, possui surpreendente potencial de atuação na seara do reconhecimento. $\mathrm{O}$ poder emanado pelo campo

mas of Justice in a "Postsocialist" Age. In: OLSON, Kevin. Adding Insult to Injury: Nancy Fraser debates her critics. London-New York: Verso, 2008, p. 20.

12 FRASER, Nancy. From Redistribution to Recognition? Dilemmas of Justice in a "Postsocialist" Age. In: OLSON, Kevin. Adding Insult to Injury: Nancy Fraser debates her critics. London-New York: Verso, 2008, p. 21.

13 FRASER, Nancy. From Redistribution to Recognition? Dilemmas of Justice in a "Postsocialist" Age. In: OLSON, Kevin. Adding Insult to Injury: Nancy Fraser debates her critics. London-New York: Verso, 2008, p. 29. 
jurídico tem capacidade tanto de (re)produzir o falso reconhecimento como atuar na afirmação de populações marginalizadas, funcionando como remédio a essa injustiça. Ainda mais: a próprias lacunas existentes nesse campo conseguem reforçar as injustiças de reconhecimento. Dessa forma, uma lei que criminaliza relações sexuais entre pessoas do mesmo sexo provoca o falso reconhecimento, mas também o faz a norma que apenas regula o casamento heterossexual, quedando-se silente a respeito da união civil homoafetiva. Nesse sentido, observa-se que o exercício do Direito, principalmente da legislação, figura com central importância na conquista de espaço a indivíduos oprimidos, ainda que, nem de longe, seja a única seara de avanço necessária. Adentrando o campo dos direitos LGBTIs, Fraser ${ }^{14}$ identifica a existência de uma reafirmação da heteronormatividade por meio da edição de leis que reforçam esse paradigma dominante e subjugam os grupos que nele não se enquadram, classificados como desviantes.

Ressalta-se, assim, que a produção legislativa e jurisprudencial que posicione os LGBTIs enquanto sujeitos de direitos é etapa essencial para seu reconhecimento e para a consequente diminuição da violência física e simbólica sofrida por eles.

É com base nessa construção teórica que se entende o Direito Internacional como potencial emanante de reconhecimento, capaz de inserir os indivíduos invisibilizados na vida social. Todavia, esse reconhecimento não pode ser apenas pela via judicial ou por meio de normativas sem qualquer força vinculante. $\mathrm{O}$ texto positivado é essencial à legitimidade e à manutenção do reconhecimento fornecido pelo Direito. Ainda mais: é dotado de fortemente de poder simbólico, uma vez que as próprias normas que impedem a participação paritária dos LGBTIs na sociedade são sedimentadas pelas práticas sociais e reforçadas por um babitus de reiteração de costumes tradicionalmente idealizados; sendo, portanto, o registro escrito da garantia de direitos etapa essencial para se alcançar o reconhecimento. ${ }^{15}$

Sendo assim, considera-se um instrumento internacional escrito com caráter vinculante indispensável ao avanço na luta pelo reconhecimento da população

14 FRASER, Nancy. Heterosexism, Misrecognition, and Capitalism: A Response to Judith Butler. Social Text, Durham, v. 0, n. 52/53, 1997, p. 283.

15 BOURDIEU, Pierre. O Poder Simbólico. Lisboa: Edições 70, 2015, p. 19-26.
LGBTI e garantia dos direitos que até hoje lhes são privados. O referido instrumento seria a própria fonte de empoderamento desses indivíduos perante seus opressores.

\section{UMA PERSPECTIVA LGBTI SOBRE A LEGISLAÇÃO INTERNACIONAL DE DIREITOS HUMANOS}

São inegáveis os avanços do reconhecimento de direitos aos LGBTIs ao longo dos últimos anos, seja na seara nacional ou internacional. Foram conquistas importantes, a maioria delas alcançadas pela via judicial ${ }^{16}$, que têm permitido a esses indivíduos viverem com mais dignidade e menos medo em nossa sociedade. Todavia, qualquer avanço parece estrondoso, quando comparado ao cenário anterior no qual os LGBTIs não eram considerados, nem mesmo, seres humanos. Desse modo, ainda hoje, há muito que se avançar para que eles usufruam de todos os direitos garantidos aos demais cidadãos e que não mais precisem se esconder, culpar ou menosprezar por serem quem são.

A partir de uma análise dogmática, os direitos sexuais possuem duas dimensões de proteção no Direito Internacional, que pode se dar, ainda, em duas modalidades diferentes. Segundo André de Carvalho Ramos, ${ }^{17}$ as duas dimensões seriam: a positiva, que diz respeito à garantia de autonomia às pessoas LGBTI, permitindo-as exercer sua cidadania plenamente; e a negativa, que concerne a proibição de discriminação dessas pessoas. Por outro lado, o autor assevera, ainda, que essa proteção pode ocorrer de maneira direta, com base na edição de normativas que consagrem direitos substantivos específicos a essa população; ou, ainda, indireta, que se dá por meio da interpretação ampliativa de disposições genéricas já existentes, como do direito à igualdade. Como será demonstrado, a proteção desses direitos na ordem internacional se dá, quase que absolutamente, pela via indireta. Ademais, destaca-se, ainda, que tal forma proteção indireta pode ocorrer, além do direito à igualdade, dicotomicamente, pelo: 1) direito à liberdade, que marca

16 LELIS, Rafael Carrano. Direitos Humanos e Reconhecimento: uma análise da tutela internacional dos direitos LGBTTIs. In: SALLES, Denise et al. Direito Internacional, Comunidade e Relações Internacionais. Rio de Janeiro: Multifoco, 2017, p. 103106.

17 RAMOS, André de Carvalho. Curso de Direitos Humanos. São Paulo: Saraiva, 2017, p. 847. 
o reconhecimento dessa população, delineando sua liberdade sexual e fortemente caracterizando sua existência digna; ou, por outro lado, 2) o direito à privacidade, que relega a sexualidade e identidade de gênero às esferas privadas e individuais, invisibilizando a existência dos LGBTIs e impossibilitando o livre exercício de sua cidadania de maneira digna.

Desse modo, o Direito Internacional, especialmente o Direito Internacional dos Direitos Humanos ${ }^{18}$, teve, e vem tendo, um importante nessa evolução do reconhecimento de direitos. No entanto, uma análise detalhada de toda a legislação internacional, a partir tratados e outras fontes de Direito Internacional, revela o quadro precário em que se encontra a tutela dos direitos LGBTIs. Não há qualquer documento vinculante que preveja direitos materiais em espécies e apenas um (e de alcance regional!) no qual há vedação expressa à discriminação ${ }^{19}$ em razão de orientação sexual e identidade e expressão de gênero.

\subsection{O sistema global de proteção dos Direitos Humanos}

Como ponto de partida do presente estudo, iniciou-se a análise pelo que se convencionou chamar de Carta Internacional dos Direitos Humanos ${ }^{20}$, composta pela Declaração Universal dos Direitos Humanos (DUDH),

18 Adota-se aqui um recorte metodológico que privilegia o Direito Internacional dos Direitos Humanos strictu sensu, de modo que não serão analisados os diplomas referentes ao Direito Internacional Humanitário, ao Direito Internacional dos Refugiados e ao Direito Penal Internacional. No entanto, deve-se destacar que nos últimos dois campos mencionados há relevante debate relacionado à proteção de pessoas LGBTIs em suas respectivas esferas de proteção, nesse sentido: JANSEN, Sabine; SPIJKERBOER, Thomas. Fleeing Homophobia: Asylum Claims Related to Sexual Orientation and Gender Identity in the EU. Amsterdam: COC Nederland - Vrije Universiteit Amsterdam, 2011. Disponível em: https://ssrn.com/ abstract=2097783; FERREIRA, Gustavo Bussmann. A proteção da orientação sexual e identidade de gênero diversas na corte penal internacional: Entre Realpolitiks E Os Direitos Humanos. Revista de Direito Internacional, Brasília, v. 14, n. 2, 2017 p. 312-329.

19 O Tratado de Roma, de 25 de março de 1957, que dispões acerca da criação da Comunidade Europeia de Energia Atômica, a partir de sua emenda realizada pelo Tratado de Amsterdã de 1997, passou a prever, em seu artigo 6-A, que seu Conselho poderia promover ações de combate a discriminação, dentre outras, em razão de orientação sexual. Todavia, não se enquadra esse texto como uma vedação à discriminação, uma vez que ele apenas permite a realização de ações de combate à discriminação, sem criar qualquer espécie de dever de respeito ou proibição de discriminação.

20 RAMOS, André de Carvalho. Teoria Geral dos Direitos Humanos na Ordem Internacional. São Paulo: Saraiva, 2017, p. 105 juntamente ao Pacto Internacional de Direitos Econômicos Sociais e Culturais (PIDESC) e o Pacto Internacional de Direitos Civis e Políticos (PIDCP). Essa escolha se deu em razão do alcance normativo desses documentos, assim como pela abrangência dos direitos neles contidos.

No que toca à DUDH, seu artigo II.1, ao tratar da abrangência dos direitos estabelecidos, determina a ausência de distinção por diversas razões, como de raça, cor e sexo, mas não menciona orientação sexual ou identidade de gênero, possibilitando apenas que essas características sejam tratadas como "qualquer outra condição". Em seu art. VII, ao tratar da vedação à discriminação, não se vale de rol exemplificativo como no artigo II, estabelecendo proteção contra "qualquer discriminação que viole a presente Declaração". Por fim, em seu artigo XVI.1, menciona o direito ao casamento como sendo de "homens e mulheres maior de idade", excluindo de seu âmbito de proteção os relacionamentos que não sejam heteroafetivos.

O PIDESC, ao vedar discriminações em seu texto, no artigo segundo, o faz apenas referindo-se a "motivos de raça, cor, sexo, língua, religião, opinião política ou qualquer outra opinião, origem nacional ou social, fortuna, nascimento, qualquer outra situação", sem fazer qualquer menção a direitos de pessoas homossexuais, bissexuais, trans e intersex. Da mesma forma, o PIDCP, em seus artigos $2^{\circ}, 4^{\circ}, 24$ e 26 , faz referência, apenas, à proibição de distinção ou tratamento desigual no que se refere à "raça, cor, sexo, língua, religião, opinião política ou de outra índole, origem nacional ou social, posição econômica, nascimento ou qualquer outra condição social". Ainda mais, em seu artigo 23, o referido Pacto também reconhece o direito ao matrimônio e formação de família apenas a casais heteroafetivos, ou seja, entre um homem e uma mulher.

Apesar de os três diplomas analisados terem sido editados há quase 60 anos e em meio a acirrada crise na política mundial, o Direito Internacional dos Direitos Humanos continuou silente em relação aos LGBTIs mesmo no intenso desenvolvimento legislativo que ocorreu posteriormente ${ }^{21}$. Nas décadas que se seguiram, foram elaborados diversos tratados de alcance global que visavam à proteção e ao combate à discriminação de diversos grupos vulneráveis, mas nenhum deles vol-

21 RAMOS, André de Carvalho. Teoria Geral dos Direitos Humanos na Ordem Internacional. São Paulo: Saraiva, 2017, p. 105 
tado à discriminação por orientação sexual e identidade de gênero. Na perspectiva do reconhecimento da população LGBTI, a ausência expressa (e simbólica) de seus integrantes no texto normativo representa uma grande lesão à estima e ao status social desses indivíduos.

Desse modo, pode-se apontar que o sistema global começa a traçar o paradigma do que chamamos de Direito Internacional Monocromático, não dedicando esforços suficientes à proteção das diversas sexualidades e identidades de gêneros e relegando sua proteção às instáveis interpretações do termo "outra condição".

\subsection{Os sistemas regionais de proteção dos Direitos Humanos}

Voltando a investigação para os planos regionais, tem-se, mais uma vez, evidenciada a lacuna normativa referente à garantia de direitos LGBTIs. A Carta da Organização dos Estados Americanos (OEA), ao dispor sobre os princípios que regem a organização, indica, na alínea 1 de seu artigo terceiro, que "l) os Estados americanos proclamam os direitos fundamentais da pessoa humana, sem fazer distinção de raça, nacionalidade, credo ou sexo", mais uma vez escancarando a invisibilização sofrida pelos LGBTIs nesses documentos.

Do mesmo modo, o Pacto de São José da Costa Rica, em seu artigo $1^{\circ}(1)$ garante a não discriminação dos Estados signatários da Convenção "por motivo de raça, cor, sexo, idioma, religião, opiniões políticas ou de qualquer outra natureza, origem nacional ou social, posição econômica, nascimento ou qualquer outra condição social". Ademais, a mesma Convenção dispõe, em seu artigo 17(2), que o casamento e a formação de família somente se darão entre um homem e uma mulher, excluindo dezenas de outros arranjos familiares possíveis de serem concebidos.

Ainda nesse sentido, dispõem a Convenção Europeia dos Direitos do Homem e a Carta Africana de Direitos Humanos e dos Povos. O documento europeu, em seu artigo 14, proíbe discriminações em razão de "sexo, raça, cor, língua, religião, opinião política ou outra opinião, origem nacional ou social, a pertença a uma minoria nacional, a riqueza, o nascimento ou qualquer outra situação". A Carta Africana, por sua vez, o faz em seu artigo segundo garantindo o gozo de direitos e liberdades sem distinção de "raça, etnia, grupo, cor, sexo, língua, religião, opinião política ou qualquer ou- tra opinião, origem nacional e social, renda, nascimento ou outro status". Como pode ser observado, ambos os documentos, mais uma vez, não especificam quaisquer dos grupos LGBTIs com relação ao direito à não discriminação ${ }^{22}$.

Como já explicitado, apesar da inexistência de menção expressa aos LGBTIs nos textos de quaisquer tratados, os chamados treaty bodies têm, sistematicamente, definido a reinterpretação da disposição normativa, de forma a incluir a proteção a LGBTIs nos termos "Outros status" ou "outra condição social" 23, presentes tanto nos documentos de alcance global, como naqueles regionais, característica marcante do Direito Internacional Monocromático.

Não obstante, ainda que importante tal esforço hermenêutico para a inclusão desses indivíduos, indicar que eles já são contemplados por essas previsões genéricas (e que, portanto, não há necessidade de novas leis) não somente ignora o forte poder simbólico e de reconhecimento carregados pela menção expressa de proteção a um grupo, mas também desmobiliza e desmerece a luta para o reconhecimento dos LGBTIs enquanto sujeitos de direitos. No entanto, essa ideia é defendida, até mesmo, pela Organização das Nações Unidas, ${ }^{24}$ indicando que "a proteção de pessoas baseada na orientação sexual e identidade de gênero não requer a criação de novas leis ou direitos especiais para pessoas LGBT".

Nesse cenário, as pessoas LGBTIs se veem à mercê de questões conjunturais para o reconhecimento de seus direitos, ocasionando uma grande insegurança jurídica, demarcando o campo de forma incipiente e repleta

22 Com relação ao Sistema Africano, merece destaque, ainda, a resolução número 275 adota pela Comissão Africana em maio de 2014, que condena a violência e os abusos cometido contra pessoas com base na sua orientação sexual e identidade de gênero, indicando aos Estados que tomem medidas para solucionar a situação. ORGANIZATION OF AFRICA UNITY (OAU). African Commission on Human and Peoples' Rights. 275: Resolution on Protection against Violence and other Human Rights Violations against Persons on the basis of their real or imputed Sexual Orientation or Gender Identity. Luanda: maio 2014. Disponível em: < http:// www.achpr.org/sessions/55th/resolutions/275/>. Acesso em: 03 fev. 2018.

23 O'FLAHERTY, Michael. Sexual Orientation and Gender Identity. In: MOECKLI, Daniel; SHAH, Sangeeta; SIVAKUMARAN, Sandesh. International Human Rights Law. Oxford: Oxford University Press, 2014, p. 315.

24 ORGANIZAÇÃO DAS NAÇÕES UNIDAS (ONU). Escritório do Alto Comissariado para os Direitos Humanos. Nascidos Livres e Iguais: orientação sexual e identidade de gênero no regime internacional de direitos humanos. Brasília: UNAIDS, 2013, p. 11. 
de incertezas. À guisa de exemplificação, pode-se aludir à discussão em torno do direito ao casamento: a própria Corte Europeia de Direitos Humanos já julgou favorável e contrariamente ao exercício desse direito por casais do mesmo sexo, enquanto o Comitê de Direitos Humanos já se pronunciou oficialmente expressando que o casamento homoafetivo não é protegido pelo Pacto Internacional de Direitos Civis e Políticos. ${ }^{25}$

No ano de 2013, a partir de articulação conduzida pelo Estado brasileiro, foi aprovada pela Assembleia Geral da OEA o primeiro (e até o momento o único) documento internacional de caráter vinculante no qual há menção a LGBTIs: a Convenção Interamericana Contra Toda Forma de Discriminação e Intolerância.

$\mathrm{O}$ artigo $1^{\circ}(1)$ da referida Convenção veda a discriminação, entre outros motivos, em virtude de "orientación sexual, identidad y expresión de género”. Não obstante essa previsão seja pioneira no Direito Internacional, está longe de ser suficiente. Ademais, além de o documento possuir eficácia apenas regional, mesmo entre os países que compõem o sistema interamericano houve baixíssima adesão. De um total de 35 membros, somente 10 assinaram o documento, com destaque para a ausência de países de grande influência, como Estados Unidos, México e Canadá.

Destaca-se, de maneira positiva, todavia, que a aprovação dessa Convenção se mostra como mais um sinal do recente engajamento recente do Sistema Interamericano na temática LGBTI, reforçado a partir da produção do documento "Violências contra pessoas LGBTI" lançado pela CIDH (2015), fruto do trabalho desenvolvido pela Relatoria Sobre os Direitos das Pessoas LGBTI; e da realização de audiência pública, pela Corte IDH, para a formação de Opinião Consultiva (OC) concernente a direitos LGBTIs em 17 de maio de 2017.

A OC foi divulgada em 24 de novembro de 2017 e significou uma importante consolidação do entendimento da Corte em relação à proteção de pessoas LGBTIs sob os marcos normativos do Direito Internacional dos Direitos Humanos. O pedido inicial formulado pela Costa Rica pediu ao tribunal que se pronunciasse sobre a abrangência dos artigos 11.2; 18 e 24 da Convenção Interamericana em relação ao reconhecimento do

25 O'FLAHERTY, Michael. Sexual Orientation and Gender Identity. In: MOECKLI, Daniel; SHAH, Sangeeta; SIVAKUMARAN, Sandesh. International Human Rights Law. Oxford: Oxford University Press, 2014, p. 311. direito de adequação do nome civil com a identidade de gênero e também à igualdade dos reflexos de direitos patrimoniais do casamento hetero e homoafetivo. A decisão da Corte foi que o direito de adequação dos registros públicos e documentos de identidade de acordo com a identidade de gênero autopercebida encontra-se tutelado pela atual redação da Convenção e, ainda, que os Estados não devem condicionar esse direito a procedimentos cirúrgicos ou tratamentos hormonais. Decidiu, também, que a Convenção protege o vínculo familiar que se origina de uma relação homoafetiva e que os Estados devem reconhecer e garantir todos os direitos derivados dessa relação.

Diante do exposto neste subtópico, tem-se que, apesar do recente engajamento Interamericano, também os sistemas regionais e seus diplomas normativos ajudam a compor a ordem monocromática que sustenta o atual paradigma do Direito Internacional, protegendo os direitos LGBTIs de forma tímida e indireta.

\subsection{Normativas da Organização das Nações Unidas}

Partindo para a investigação de outras fontes de Direito Internacional que tratem dos direitos de pessoas LGBTI, foram encontradas quatro resoluções do Conselho de Direitos Humanos da ONU abordando a matéria.

No ano de 2011, passou no Conselho a resolução A/HRC/RES/17/19, encomendando um estudo pelo Alto Comissariado a respeito da existência de leis discriminatórias e violência contra pessoas com base em sua orientação sexual ou identidade de gênero. Sua aprovação se deu com 23 posicionamentos favoráveis, 19 contrários e três abstenções. Salta aos olhos a proximidade entre o número de Estados a favor da proposta (vinte e três) e daqueles que não apoiaram o conteúdo da resolução (22, somando votos contrários e abstenções), reforçando a falta de compromisso estatal com a instauração de uma ordem de proteção efetiva a esses indivíduos.

Três anos mais tarde, o mesmo Conselho aprovou a resolução $A / H R C / R E S / 27 / 32$, assinalando sua tomada de conhecimento da produção do relatório "Discriminatory laws and practices and acts of violence against individuals based on their sexual orientation and gender identity '26 elabora-

26 O relatório foi introduzido por meio da resolução $A / H R C /$ RES/19/41. ORGANIZAÇÃO DAS NAÇÕES UNIDAS (ONU). 
do pela Alto Comissariado das Nações Unidas para os Direitos Humanos ainda no ano de 2011.

Pouco depois, em 2016, o Conselho aprovou a resolução $A / H R C / R E S / 32 / 2$, à qual se considerou um marco histórico no reconhecimento das pessoas LGBTIs enquanto sujeitos de direitos e dignos de proteção pelos Direitos Humanos. No referido documento, o Conselho condenou a violência os atos de violência contra LGBTIs ao redor de todo o mundo e decidiu indicar um expert independente ${ }^{27}$ na matéria de combate à discriminação e violência baseados em orientação sexual e identidade de gênero.

Constituído para um mandato de três anos, o expert possui dentre os seus objetivos: avaliar a possibilidade de implementação dos instrumentos internacionais de Direitos Humanos no combate a essas formas de discriminação e violência; conscientizar a população global a respeito da existência dessas formas de violência; e cooperar com os Estados para a implementação de medidas para a proteção dos LGBTIs. Ponto preocupante, contudo, reside nos números da votação da resolução, foram 23 votos favoráveis, 18 contrários e seis abstenções, ou seja, uma quantidade maior de não apoiadores (24 no total) do que de Estados a favor da resolução.

Mais recentemente, em 19 de abril de 2017, a resolução $A / H R C / 35 / 36$ introduziu o primeiro relatório produzido por Muntarbhorn. Nele, é feito um breve panorama acerca das formas de violência enfrentadas pelos LGBTIs, sendo destacada a necessidade de proteção específica para esses indivíduos, e são traçadas seis metas fundantes para o avanço na temática:

\footnotetext{
1) descriminalização de relações sexuais consensuais entre pessoas do mesmo sexo; 2) medidas antidiscriminação efetivas; 3) reconhecimento legal de identidade de gênero; 4) desestigmatização ligada à despatologização; 5) inclusão sociocultural; e 6) promoção de educação e empatia.
}

Ainda com relação ao papel das Nações Unidas, merece menção a campanha "Livres e Iguais" (Free and

Conselho de Direitos Humanos. A/HRC/RES/19/41, 2011b. Disponível em: <http://www.ohchr.org/Documents/Issues/ Discrimination/A.HRC.19.41_English.pdf $>$. Acesso em: 01 jun. 2017.

27 Foi, à época, indicado para essa ocupação o professor de direito Vitit Muntarbhorn da Universidade Chulalongkorn, em Bangkok, na Tailândia, cujo exercício da função durou de agosto de 2016 a outubro de 2017. Posteriormente, no final de 2017, foi eleito um novo expert para o cargo, o costarriquenho Victor Madrigal-Borloz, que começou suas atividades na posição em 01 de janeiro de 2018.
Equal) lançada pelo escritório de Direitos Humanos da organização. Iniciada em julho de 2013, seu objetivo é promover a igualdade de direitos e um tratamento justo para as pessoas LGBTI e vem exercendo um importante papel no tocante ao aumento da visibilidade dessa população.

Também na ONU, foi elaborado em 2017 um documento do Alto Comissariado para os Direitos Humanos que visa estabelecer um standard de conduta para as empresas em relação à promoção dos direitos e à vedação de discriminação de pessoas LGBTIs. ${ }^{28}$ Apesar de demonstrar um primeiro passo no envolvimento de agentes corporativos no processo de consolidação desses direitos, não sinaliza um compromisso efetivo com os indivíduos LGBTIs. Isso porque, como o próprio documento aponta, ele foi confeccionado com base no Pacto Global e nos Princípios Orientadores de Empresas e Direitos Humanos, dois marcos voluntaristas (i.e., não impõem às empresas qualquer forma de sanção no caso de descumprimento deles) que vem sendo frequentemente desrespeitados. Assim, apesar de chamar a atenção do Direito Internacional para o fato de que as empresas são, potencial e concretamente, violadoras de direitos LGBTIs, não contribui para uma ampliação efetiva da proteção desses indivíduos.

Destaque-se que, apesar dessas diversas iniciativas encabeçadas pela ONU, a organização ainda aposta em regular a matéria por meio de soft law, demonstrando a pouca importância que concede aos direitos LGBTIs. Nesse sentido, contribui, também, para o estabelecimento da ordem monocromática ao apostar em normativas não vinculantes em vez de, por exemplo, liderar a elaboração de um tratado internacional que trate, especificamente, dos direitos dessas pessoas e sua proteção.

\subsection{Os Princípios de Yogyakarta}

Por fim, não se pode deixar de mencionar o documento mais consistente até hoje produzido acerca da temática no âmbito internacional: os Princípios de Yogyakarta (Yogyakarta Principles). Encabeçado pela Inter-

28 ORGANIZAÇÃO DAS NAÇÕES UNIDAS (ONU). Alto Comissariado das Nações Unidas para Direitos Humanos. Tackling Discrimination against Lesbian, Gay, Bi, Trans, \& Intersex People: standards of conduct for business. Nova Iorque, 2017a. Disponível em: <https://www.unfe.org/wp-content/uploads/2017/09/UN-Standards-of-Conduct.pdf>. Acesso em 15 out. 2017. 
national Comission of Jurists e pelo International Service for Human Rights, os princípios, finalizados no ano de 2007, foram elaborados por 29 especialistas em Direitos Humanos Internacionais, tendo o processo sido conduzido pelo professor Michael O’Flaherty.

O documento se dedica à construção de princípios para a aplicação da legislação internacional dos Direitos Humanos com relação à orientação sexual e identidade de gênero. De maneira geral, apresenta um mapeamento das violências sofridas pelos LGBTIs e a possível aplicação das normas internacionais de Direitos Humanos no combate a tais violências, estabelecendo obrigações para a efetiva implementação e extensão de cada um dos Direitos Humanos à população LGBTI. ${ }^{29}$

Mais recentemente, ao final de 2017, foram publicados um conjunto de dez princípios adicionais, que complementam o documento original, acrescentando alguns elementos, como a preocupação com a interseccionalidade das opressões sofridas. ${ }^{30}$

Todavia, é importante notar que eles não possuem caráter vinculante, seja pelo seu modo de elaboração, seja pela ausência de elementos que os transformem em costume internacional, o que diminui sua importância no cenário internacional, sendo sua aplicação facilmente afastável por qualquer tribunal.

\subsection{Delineando os resultados da análise documental}

Com base no exposto, é possível afirmar que a proteção dos direitos LGBTIs, mesmo na seara do Direito Internacional dos Direitos Humanos, é extremamente deficiente, além de incipiente, principalmente quando analisados os documentos internacionais positivos. Desse modo, a proteção desses indivíduos continua "restrita ao âmbito, muitas vezes pouco eficaz e sujeito às flutuações políticas dos sistemas internos, tanto em relação

29 THE YOGYAKARTA PRINCIPLES (YP). Principles on the application of international human rights law in relation to sexual orientation and gender identity, mar. 2007. Disponível em: <http://www.yogyakartaprinciples.org/wp/wp-content/uploads/2016/08/principles_en.pdf $>$. Acesso em: 01 jun. 2017.

30 THE YOGYAKARTA PRINCIPLES PLUS 10 (YP10). Additional principles and state obligations on the application of international human rights law in realtion to sexual orientation, gender identity, gender expression and sex characteristics to complement the Yogyakarta Principles. Geneva: nov. 2017. Disponível em: < http://yogyakartaprinciples.org/wp-content/uploads/2017/11/A5_yogyakartaWEB-2.pdf>. Acesso em: 03 fev. 2018. à existência de legislação como à efetividade da implementação desta, no sentido de ser assegurada a proteção e não discriminação de importantes minorias". ${ }^{31}$

A partir da análise documental realizada, pode-se afirmar, como resultado parcial, que, no tangente à legislação internacional positiva, confirma-se a hipótese de um Direito Internacional Monocromático. Isto é, uma ordem internacional que não se manifesta expressamente pela proteção de pessoas LGBTIs, nem mesmo veda, de forma clara, a discriminação contra elas. As poucas menções expressas encontradas estão restritas a documentos que não possuem força vinculante e nem consistem em fontes primárias do Direito Internacional, colocando vidas e direitos LGBTIs sujeitos à vontade política dos Estados.

\section{A tutela dos direitos lgbtis nas cortes INTERNACIONAIS DE DIREITOS HUMANOS}

A análise da legislação internacional no tangente à tutela de pessoas LGBTI é essencial, principalmente ao se considerar a dimensão simbólica da exclusão dessas pessoas dos referidos diplomas legais. No entanto, esse enfoque restrito pode não refletir o real nível de proteção dessa população no sistema internacional. Isso porque a jurisprudência internacional possui um papel de cristalização normativa dos Direitos Humanos, por meio de sua interpretação evolutiva. Como afirma Ramos, ${ }^{32}$ as normas de Direitos Humanos previstas nos tratados, constituições e leis internas, são sempre um ponto de partida e nunca o de chegada, sendo necessária, sempre, a análise jurisprudencial para a real aferição do âmbito de proteção dessas normas.

Esse estudo jurisprudencial deve ser feito, no entanto, sem que se olvide da importância dos meios convencionais, notavelmente dos tratados internacionais. Apoiar-se em meios não convencionais implica depender da vontade não positivada dos Estados, que é totalmente instável. Os tratados podem oferecer, ainda, além da vantagem da segurança jurídica, a constituição de treaty bodies, que são os órgãos responsáveis pela implemen-

31 ACCIOLY, Hidelbrando; SILVA, G.E do Nascimento; CASELLA, Paulo Borba. Manual de Direito Internacional Público. 22.ed. São Paulo: Saraiva, 2016, p. 523.

32 RAMOS, André de Carvalho. Processo Internacional de Direitos Humanos. São Paulo: Saraiva, 2016, p. 35-38. 
tação daquelas normas. ${ }^{33}$ Tendo em mente essa ressalva relativa à importância dos meios positivados a despeito da posição jurisprudencial, neste tópico será desenvolvido o exame da jurisprudência das cortes regionais de Direitos Humanos em matéria de direitos LGBTI.

A partir da Declaração Universal de Direitos Humanos em 1948, percebe-se uma acentuada evolução na tutela dos Direitos Humanos no plano internacional. O Direito Internacional dos Direitos Humanos se desenvolveu como forma proteção das vítimas reais e potenciais das diversas formas de dominação e poder arbitrário no seio da sociedade internacional. Seu desenvolvimento ocorre tanto no plano substantivo, pela elaboração de normas que visam à proteção do ser humano, como já abordado, quanto no plano processual, por meio de mecanismos globais e regionais que implementam tais normas. A proliferação desses mecanismos processuais, i.e., tribunais internacionais, na metade do século XX, sinaliza significativos avanços na realização da justiça internacional. ${ }^{34}$ Nesse sentido, os mecanismos regionais têm papel indispensável nessa dinâmica de proteção e implementação dos Direitos Humanos, destacando-se, entre esses, o Sistema Interamericano, Africano e Europeu de proteção de Direitos Humanos.

Nesse sentido, a Corte Interamericana de Direitos Humanos é um órgão jurisdicional que forma, em conjunto com a Comissão, o Sistema Interamericano de Direitos Humanos. Sua função é dúplice: consultiva, responsável pela interpretação das disposições da Convenção Interamericana; e jurisdicional propriamente dita, atuando no julgamento dos Estados acusados de violações aos Direitos Humanos e aplicando diretamente as normas de Direito Internacional, especialmente aquelas contidas no Pacto de São José da Costa Rica. ${ }^{35}$

No continente africano, o sistema de proteção adota a mesma estrutura organizacional, dividindo-se em uma Comissão e na Corte Africana de Direitos Humanos e dos Povos. Composta por 11 juízes, a Corte atua de forma complementar à Comissão, promovendo a proteção dos Direitos

33 RAMOS, André de Carvalho. Processo Internacional de Direitos Humanos. São Paulo: Saraiva, 2016, p. 115.

34 CANÇADO TRINDADE, Antônio Augusto. Desafios E Conquistas Do Direito Internacional Dos Direitos Humanos No Início Do Século XXI. Disponível em: < https:/ /www.oas.org/ dil/esp/407-490\%20cancado $\% 20$ trindade $\% 20$ OEA $\% 20$ CJI $\% 20$ \%20.def.pdf>. Washington: OEA, 2006. Acesso:17 mar. 2017.

35 PIOVESAN, Flávia. Direitos Humanos e Justiça Internacional: um estudo comparativo dos sistemas regionais europeu, interamericano e africano. São Paulo: Saraiva, 2014, p. 128-130.
Humanos no continente africano. Nesse sentido, os casos podem chegar até à Corte de duas maneiras: direcionados pela Comissão, diante do não cumprimento pelo Estado de alguma de suas recomendações; ou apresentado diretamente pelo indivíduo afetado, mas apenas se seu país estiver dentre aqueles que autorizam esse tipo de demanda. ${ }^{36}$ Diante da ausência do instituto da Corte no texto da Carta Africana de Direitos Humanos e dos Povos, sua criação se deu mais recentemente e seu primeiro julgamento ocorreu apenas no ano de 2009, o que pode explicar a ausência de casos relativos à temática LGBTI, como veremos a seguir.

Finalmente, o Sistema Europeu, o mais consolidado dentre os três, foi originalmente criado com sua composição formada por três órgãos principais: a Comissão e a Corte Europeias de Direitos Humanos e um Comitê de Ministros. Após diversas reformas implementadas por meio de protocolos à Convenção Europeia de Direitos Humanos, a Comissão foi extinta, permanecendo apenas o Comitê e a Corte, que passou a concentrar toda a atividade jurisdicional e a se estruturar de forma mais organizada, permitindo uma densa atuação na consolidação dos Direitos Humanos na região. ${ }^{37}$

\subsection{Metodologia de busca}

Explicita-se, neste subtópico, a metodologia de busca empregada para a constatação dos casos relativos à temática LGBTI nas cortes internacionais de Direitos Humanos, que subsidiaram a pesquisa realizada. A pretensão da investigação é identificar casos que tratem de direitos dos LGBTIs de forma geral e, também, de casos específicos relacionados às pessoas trans, por se tratar de um grupo de pessoas especialmente marginalizadas, até mesmo, dentro da população LGBTI.

\subsubsection{A Corte Africana de Direitos Humanos e dos Povos}

No primeiro acesso ao site oficial Corte Africana de Direitos Humanos e dos Povos ${ }^{38}$, constatou-se que

36 HEYNS, Christof; KILLANDER, Magnus. Africa. in: MOECKLI, Daniel; SHAH, Sangeeta; SIVAKUMARAN, Sandesh. International Human Rights Law. Oxford: Oxford University Press, 2014, p. 452-454.

37 GREER, Steven. Europe. In: MOECKLI, Daniel; SHAH, Sangeeta; SIVAKUMARAN, Sandesh. International Human Rights Law. Oxford: Oxford University Press, 2014, p. 423-425.

38 http://www.african-court.org/en/. Acesso em: julho de 2017. 
a referida Corte não possui qualquer sistema de busca de jurisprudência. Dessa forma, foram analisados os acórdãos integrais de todos os casos disponíveis na sessão "Case", sendo feita a leitura individual de todo seu conteúdo pelos pesquisadores. Em relação aos 35 casos disponíveis como "finalizados" na data de 5 de junho de 2017, nenhum possuía pertinência, direta ou indireta, com a temática LGBTI. Desse modo, constatou-se que a discussão acerca dos direitos LGBTIs não foi, até o momento, debatida pela Corte Africana; carecendo-se, portanto, de qualquer jurisprudência relativa à temática passível de ser analisada.

É importante notar que a ausência de casos que discutam a violação de direitos dos LGBTIs não significa que os Estados submetidos a esse órgão jurisdicional não cometam tais violações. Muito pelo contrário, o continente africano é um dos mais conservadores quando se trata de avanço de direitos relacionados à orientação sexual e à identidade de gênero, sendo a homossexualidade criminalizada, ainda hoje, em cerca de 30 de seus países ${ }^{39}$.

Desse modo, o fato de essas discussões não terem nem mesmo alcançado a Corte Africana de Direitos Humanos ilustra, mais uma vez, as características de um Direito Internacional Monocromático, uma vez que, diante de sua total invisibilidade, as demandas dessa população nem chegaram a ser propostas na Corte, seja para serem reconhecidas, seja para serem negadas.

\subsubsection{A Corte Interamericana de Direitos Humanos}

Diante da impossibilidade de serem examinados todos os casos da Corte Interamericana de Direitos Humanos, que são numerosos, foi feita uma análise por amostragem a partir de busca realizada na plataforma "Buscador Jurídico de Derechos Humanos", disponível no site da própria $\operatorname{Corte}^{40}$. $\mathrm{Na}$ data de 5 de junho de 2017, foi inserido o termo "LGBT" 41 na referida ferramenta de busca, sendo obtido como resultado apenas

39 ANISTIA INTERNACIONAL (AI). A Crescente Maré da Homofobia na África, 2014. Disponível em: < https://anistia.org. $\mathrm{br} /$ noticias/a-crescente-mare-da-homofobia-na-africa/ $>$. Acesso em: 15 fev 2018.

40 http://www.corteidh.or.cr/. Acesso em: junho de 2017.

41 A escolha pela sigla "LGBT" se deveu ao fato de essa ser, ainda nos dias de hoje, mais comumente empregada no meio jurídico para ser referir à população LGBTI como um todo. um caso $^{42}$ (Atala Riffo and Daughters V. Chile). Posteriormente, no dia 08 de junho de 2017, foi pesquisado o termo "transexual", sendo novamente obtido como resultado apenas o caso Atala Riffo and Daughters V. Chile. Destaca-se que ambas as buscas foram realizadas definindo a língua inglesa como a padrão para os resultados. Optou-se pela Língua Inglesa por ser uma das línguas oficiais do Sistema Interamericano que coincidem com o sistema Europeu e Africano, para fins de padronização dos resultados da pesquisa.

\subsubsection{Corte Europeia de Direitos Humanos}

Para a análise dos casos do sistema europeu, acessou-se o site oficial da Corte Europeia de Direitos Humanos $^{43}$ e foi utilizada a ferramenta de busca HUDOC - Human Rights Documentation ${ }^{44}$. Valendo-se do buscador mencionado, foi inserido o termo "LGBT", sendo utilizado o filtro referente aos casos já finalizados. Foram encontrados 23 casos que possuíam decisões da corte (judgments) no dia 5 de junho de 2017. Em seguida, foi inserido o termo "transexual", na data de 8 de junho de 2017, resultando em 20 casos finalizados. Logo após as buscas, foi realizada uma análise manual dos casos encontrados, a partir da leitura do relatório de cada um dos julgados, para que se aferisse a adesão deles à temática, evitando a análise de dados incorretos. Após essa triagem, restaram 16 casos $^{45}$ dos encontrados com o termo "transexual" e 9 dos $\operatorname{casos}^{46}$ encontrados com o termo

42 Sabe-se que a Corte Interamericana já julgou um outro caso relacionado aos direitos LGBTIs (Ángel Alberto Duque v. Colombia), além de possuir outro caso pendente de julgamento (Homero Flor Freire vs. Ecuador.). Todavia, para que pudesse ser uniformizada a metodologia de seleção dos casos tanto na Corte Interamericana, quanto na Corte Europeia, optou-se por não inserir o caso Ángel Alberto Duque v. Colombia na presente análise, por ele não ter aparecido no mecanismo de busca.

43 http://www.echr.coe.int/. Acesso em: junho de 2017.

44 http://hudoc.echr.coe.int/. Acesso em: junho de 2017.

45 Case of Oliari and Others v. Italy; Case of X v. Turkey; Case of Schalk and Kopf v. Austria; Case of L. v. Lithuania; Case of Grant v. The United Kingdom; Case of B.B. v. The United Kingdom; Case of Van Kuck v. Germany; Case of I. v. The United Kingdom; Case of Christine Goodwin v. The United Kingdom; Case of $\mathrm{X}, \mathrm{Y}$ and $\mathrm{Z}$ v. The United Kingdom; Case of B. v. France; Case of Cossey v. The United Kingdom; Case of Rees v. The United Kingdom; Case of Van Oosterwijck v. Belgium.

46 Case of O.M v. Hungary; Case of Taddeucci and McCall v. Italy; Case of M.C. and A.C v. Romania; Case of Identoba and others v. Georgia; Case of Hämäläinen v. Finland; Case of M.E v. Sweden; Case of X and Others v. Austria; Case of Genderdoc-M v. Moldova; Case of Gas and Dubois v. France. 
"LGBT". Dois casos se repetem em ambas as categorias ${ }^{47}$. Destaca-se que, novamente, a busca foi realizada na Língua Inglesa, devido aos motivos já apontados de uniformização dos dados.

\subsection{Análise dos casos encontrados}

A partir dos casos encontrados pelo procedimento acima, a pesquisa utilizou o software "MAXQDA12" para que pudessem ser tabulados os resultados referentes ao estudo de cada um dos argumentos jurídicos empregados nas decisões das cortes de Direitos Humanos sobre pessoas LGBTIs.

Nesse sentido, após a leitura da íntegra de cada um dos acórdãos, definiram-se marcadores para representar o fundamento principal da decisão de cada uma das cortes. Dessa forma, foram transpostos os artigos das convenções de Direitos Humanos aludidos nas decisões para os direitos aos quais correspondiam. Em cada caso, foram observados os argumentos jurídicos principais na decisão das cortes. Foram encontrados os seguintes marcadores: direito à privacidade ${ }^{48}$; proibição à tortura combinado com direito à não discriminação; proibição à tortura de forma autônoma; direito à não discriminação de forma autônoma; direito à livre associação; direito à liberdade e segurança; direito a um recurso efetivo; direito ao casamento; questão processual (direito formal); e direito a um processo equitativo.

Em relação à Corte Interamericana $(\mathrm{CrIDH})$, a análise se restringiu ao único julgamento encontrado. Nesse caso, a Corte decidiu com fundamento nos direitos à privacidade e à não discriminação, invocando os artigos 11.2 e 24 da Convenção Americana de Direitos Humanos.

De outro modo, ao analisar os dados obtidos no tocante à Corte Europeia $(\mathrm{CEDH})$, tendo em vista o maior número de casos encontrados, foi possível analisar a tutela das pessoas LGBTIs e, ainda, de forma separada, a tutela das pessoas transexuais. A maior quantidade possibilita um entendimento mais profundo de como ocorre a tutela das pessoas LGBTIs no plano dos

47 Case of Hämäläinen v. Finland e Case of M.E v. Sweden.

48 Foi considerado englobado no "direito à privacidade", as vezes nas quais foi apresentado pelos juízes, o fundamento no direito à privacidade combinado com o direito à não discriminação. Isso porque o argumento se baseava no fato de a pessoa não poder ser discriminada em função de algo concernente à sua vida privada, posicionando, da mesma forma, a sexualidade na esfera privada.
Direitos Humanos Internacionais.

Nos casos referentes à Corte Europeia em que se utilizou o termo de busca LGBT, a proteção jurídica ocorreu, em 44\% das vezes, com fundamento no direito à privacidade (Art. 8 da $\mathrm{CEDH}), 22,2 \% \mathrm{com}$ fundamento na proibição da tortura conjugada com a vedação à Discriminação (Arts. 3 e 14) e 11.1\% com fundamento no direito à não discriminação, como mostra o gráfico da Figura 1.

\section{Figura 1}

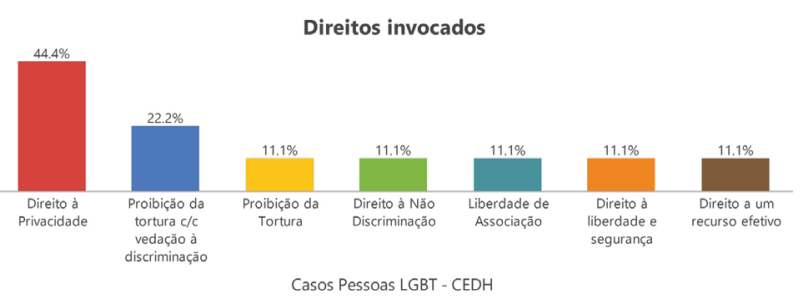

Fonte: Autoria própria

Por outro lado, em relação às pessoas transexuais, é possível notar uma utilização ainda maior do direito à privacidade como fundamento da tutela jurídica, uma vez que $87,5 \%$ dos casos foram tipificados como violações desse direito humano (Figura 2).

\section{Figura 2}

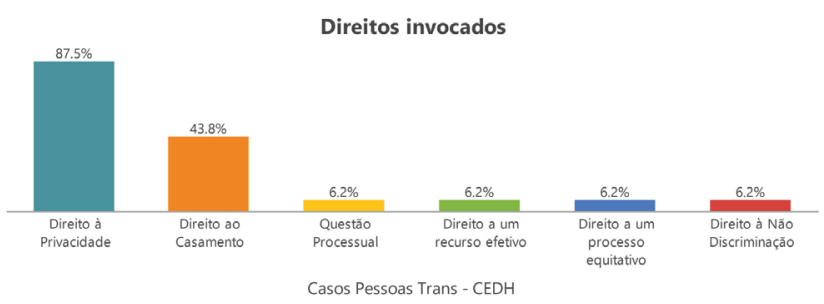

Fonte: Autoria própria

Desse modo, analisando-se os casos encontrados com os dois diferentes critérios de busca, constata-se a utilização do direito à privacidade em $72 \%$ dos casos, frequência imensamente superior a todos os outros argumentos somados (Figura 3).

\section{Figura 3}

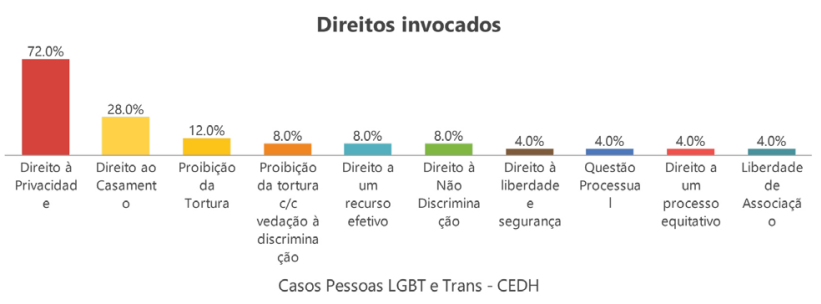

Fonte: Autoria própria. 
A partir dos resultados obtidos, é possível identificar o amplo enquadramento, principalmente na Corte Europeia, dos direitos LGBTIs percebidos a partir do direito à privacidade, o que é ainda mais evidente quando se trata das pessoas trans. Esse resultado é preocupante, principalmente, em duas esferas: primeiro, pois diminui a importância de reconhecimento de direitos materiais específicos aos LGBTIs, enquadrando-se todo e qualquer direito dentro das ideias de respeito à privacidade e a não discriminação; e ainda pior: posiciona as "sexualidades e identidades desviantes" na esfera privada, invisibilizando, mais uma vez, a luta dos LGBTIs, contribuindo, portanto, para a construção e manutenção do paradigma que denominamos de Direito Internacional Monocromático.

Renegar a proteção dos direitos desses indivíduos apenas à esfera privada significa mantê-los escondidos da sociedade e impedidos de expressar livremente suas personalidades. Isto é, a utilização desse argumento reforça a invisibilização e opressão históricas enfrentadas por esse grupo, que é impedido de exteriorizar seus sentimentos e sua própria existência para o restante da sociedade. A tutela pela via da proteção à vida privada transmite uma mensagem óbvia por meio desses órgãos de jurisdição internacional: os Direitos Humanos das pessoas LGBTIs são tutelados quando se manifestam na esfera privada e ostentar a sua existência LGBTI na esfera pública é correr o risco de não ter seus Direitos Humanos reconhecidos no direito internacional.

É compreensível que, diante da inexistência de normas específicas que regulem a temática LGBTI, os juízes se valham da interpretação ampliativa de direito genéricos já existentes, para estender sua proteção pela via indireta, como anteriormente apontado. Todavia, seria muito mais digno que essa ampliação se desse com base no direito à liberdade, construindo uma proteção à liberdade sexual e de identidade dos indivíduos; o que não somente garantiria o reconhecimento de seus direitos pelas Cortes, como também funcionaria como uma fonte de empoderamento desses indivíduos, sinalizando que estão livres para existir com dignidade e que suas existências são protegidas e reconhecidas pelo Direito Internacional dos Direitos Humanos. Assim, a proteção pela via da liberdade, que permite a esses indivíduos se expressarem com segurança, estaria muito mais próxima de construir um direito internacional diverso e "colorido", em contraposição ao atual paradigma excludente e monocromático.
É importante frisar que uma vida digna para essas pessoas envolve, justamente, poderem estar livres do armário social que sempre as condicionou. Não terem que esconder suas sexualidades ou identidades de gênero com medo de serem violentadas ou impedidas de frequentar determinados lugares. O próprio exercício de identidade trans é impossível sem a exteriorização de sua real identidade de gênero, que lhe foi negada desde o nascimento. Desse modo, a análise desses casos jurisprudenciais reforça a constatação delineada a partir do exame da legislação internacional: muito avanço ainda é necessário para que as pessoas LGBTIs alcancem a proteção merecida à luz do Direito Internacional.

\section{Consequências e perspectivas do direito INTERNACIONAL MONOCROMÁTICO}

O artigo, até o momento, dedicou-se à análise da tutela internacional dos direitos LGBTIs. Dessa forma, traçou-se um panorama crítico-analítico da previsão de proteção aos LGBTIs nas fontes legislativas do Direito Internacional, bem como na jurisprudência das cortes de Direitos Humanos no trato da matéria.

No diagnóstico apresentado, observou-se um enorme déficit com relação à proteção desses indivíduos em documentos internacionais com caráter vinculante, sem a menção expressa a direitos materiais e também à vedação à discriminação. A utilização de previsões tão genéricas para a proteção LGBTI também faz com que problemas específicos dessa população, diretamente inerentes à sua dignidade, não sejam tratadas no âmbito dos Direitos Humanos Internacionais, como a questão da retificação de registros públicos de pessoas trans ou o seu acesso ao sistema de saúde pública.

Ademais, identificou-se que a principal tutela desses direitos, realizada pelas cortes internacionais de Direitos Humanos, acontece, majoritariamente, pela via do direito à privacidade, relegando a existência das pessoas LGBTIs a um armário perpétuo e impedindo-as de se expressar livremente em meio à sociedade.

A própria gênese da expressão "armário" se dá no contexto de tutela do direito à privacidade no caso Hardwick, apreciado pela Suprema Corte estadunidense. A reprodução dessas formulações judiciais constitui óbice ao efetivo reconhecimento das pessoas que têm orientações sexuais ou identidade de gênero alheias ao padrão 
heterocisnormativo, estabelecendo limitações ao seu modo de existência. A vinculação da proteção dessas minorias à privacidade as confina na estrutura opressora do armário. ${ }^{49}$ Para além da opressão simbólica promovida pela supressão da publicidade dessas afetividades e identidades, o armário perpetua o risco iminente de violências materiais. Isso porque é uma estrutura insegura: pode ser desconstituído a qualquer momento, até mesmo contra a vontade daqueles que o habitam..$^{50}$

Como aponta Borrillo, ${ }^{51}$ restringir o direito dessas pessoas à esfera individual é uma forma de frear a ameaça que eles representam à estrutura conservadora de diferenciação dos sexos. Desse modo, percebe-se que o Direito Internacional atua de forma monocromática, isto é, ignorando a imensa diversidade de sexualidades e identidades de gêneros existentes e reforçando o status quo que é estruturado ao entorno da heterossexualidade compulsória, que é vista como regra, o mesmo se aplicando às diversas identidades de gênero desviantes do padrão cisnormativo.

Ressalta-se, ainda, que esse panorama atual é reflexo direto da vertente liberal da homofobia, que reconhece que as esferas individuais como sagradas, sem se preocupar em garantir direitos para além delas àqueles que são marginalizados. É dessa forma que esse tipo de homofobia "confina os homossexuais no silêncio da vida privada; as dicotomias privado/público, dentro/fora, interior/exterior organizam a hierarquia das sexualidades, reservando a posição visível para um aspecto, mantendo o outro em segredo". ${ }^{52}$ Assim, a atual sistemática do Direito Internacional tem contribuído para que os LGBTIs sejam "mantidos em segredo".

Constatar que, em pleno século XXI, os LGBTIs ainda não possuem direitos consolidados no cenário internacional, apesar de previsível, é avassalador. Indivíduos historicamente oprimidos e discriminados con-

49 SEDGWICK, Eve Kosofsky. A epistemologia do armário. Cad. Pagu, Campinas, n. 28, p. 19-54, June 2007. Disponível em: $<$ http://www.scielo.br/scielo.php?script=sci_arttext\&pid=S010483332007000100003\&lng=en\&nrm=iso >. acesso em $10 \mathrm{dez}$. 2017. http://dx.doi.org/10.1590/S0104-83332007000100003.

50 JANSEN, Sabine; SPIJKERBOER, Thomas. Fleeing Homophobia: Asylum Claims Related to Sexual Orientation and Gender Identity in the EU. Amsterdam: COC Nederland - Vrije Universiteit Amsterdam, 2011. Disponível em: https://ssrn.com/ abstract $=2097783$. Acesso em: 27 dez. 2017.

51 BORRILLO, Daniel. Homofobia: história e crítica de um preconceito. Belo Horizonte: Autêntica, 2016, p. 75-76.

52 BORRILLO, Daniel. Homofobia: história e crítica de um preconceito. Belo Horizonte: Autêntica, 2016, p. 77. tinuam a sofrer com a violência física e simbólica irradiada pela sociedade, sem poder encontrar amparo em instrumentos jurídicos.

Nesse cenário, é essencial que sejam propostas alternativas a esse Direito Internacional Monocromático, visando à superação desse paradigma e à efetiva proteção desses indivíduos. Desse modo, faz-se imprescindível a elaboração de um tratado internacional sobre a matéria, com protagonismo dos LGBTIs, pois, somente assim, é possível a formulação de um documento que abarque todas as necessidades advindas da vivência diária dessa população. Portanto, é essencial que essa construção normativa ocorra de baixo para cima (bottom up), isto é, a partir daqueles diretamente afetados.

Não há duvidas de que a sujeição dos Estados às cortes internacionais de Direitos Humanos paulatinamente força a revisão de conceitos clássicos, como a soberania, e avançam significativamente na humanização do Direito Internacional. No entanto, os sistemas globais e regionais de proteção dos Direitos Humanos são constituídos, ainda, dentro de uma lógica estadocêntrica, uma vez que o reconhecimento dessas normas de proteção e a instituição desses tribunais é subordinada à vontade e colaboração dos próprios Estados.

Desse modo, há que se entender o Direito Internacional dos Direitos Humanos enquanto campo político que, se ocupado apenas pelos Estados, possui evidentes limites na tutela do ser humano, justamente como ocorre em relação às pessoas LGBTIs.

Nesse sentido, torna-se necessária a atuação da sociedade civil transnacional como instância criativa do Direito Internacional, construindo-o de forma contra hegemônica, de baixo para cima.

Da experiência trazida pelo movimento transnacional pelos direitos das comunidades indígenas, extrai-se que o papel dos movimentos sociais deve se basear na coligação entre esforços locais, regionais e globais, exercidos tanto na esfera legal, quanto na esfera política. ${ }^{53}$ De maneira semelhante, pode-se analisar a atuação da sociedade civil organizada no âmbito de criação do Tribunal Penal Internacional. Seu processo de elaboração

53 RODRIGUEZ-GUARAVITO, César A.; ARENAS, Luis Carlos. Indigenous rights, transnational activism, and legal mobilization: the struggle of the U'wa people in Columbia. in: RODRIGUEZGUARAVITO, César A.; SANTOS, Boaventura de Sousa. Law and Globalization from Below: towards a cosmopolitan legality. Cambridge: Cambridge University Press, 2005, p. 260-261. 
ilustra uma intensa participação de ONGs, que é dividida em quatro etapas: suporte ideológico, elaboração de substrato técnico e teórico sobre o tema, acompanhamento das negociações intergovernamentais e suporte aos delegados representantes no processo. ${ }^{54}$ Contornos muito semelhantes podem ser observados no atual processo de discussão sobre um instrumento vinculante sobre empresas e Direitos Humanos, que conta com ampla participação da sociedade civil para impulsionar as mudanças no ordenamento internacional. ${ }^{55}$

Ademais, como indica Fraser, a implementação de demandas por reconhecimento devem sempre ser guiadas pelos posicionamentos emanados dos movimentos sociais, que são os mais capacitados a delinear as necessidades de alteração normativa, em virtude das violências e violações por eles sofridas. ${ }^{56}$

Sendo assim, também a solução ao presente Direito Internacional Monocromático deve se apresentar de forma contra hegemônica. Isto é, com a indispensável participação dos LGBTIs, ilustrando uma perspectiva de construção normativa de baixo para cima, na qual sejam empoderados os próprios indivíduos oprimidos e sejam eles a moldarem as normativas que irão tutelar seus direitos. Ressalta-se que a sociedade civil organizada vem se articulando de maneira internacional para as questões LGBTI desde a década de $1990 .{ }^{57}$ Nesse sentido, destaca-se que uma das primeiras tentativas de estabelecer a pauta LGBTI no âmbito da ONU, pela chamada "Brazilian Resolution" (E/CN.4/2003/L.92*),

54 PUREZA, José Manuel. Defensive and oppositional counter-hegemonic uses of international law: from the International Criminal Court to the common heritage of humankind. in: RODRIGUEZ-GUARAVITO, César A.; SANTOS, Boaventura de Sousa. Law and Globalization from Below: towards a cosmopolitan legality. Cambridge: Cambridge University Press, 2005, p. 270.

55 ROLAND, Manoela Carneiro; ANGELUCCI, Paola Durso. O Processo de Elaboração do Tratado de Direitos Humanos e Empresas: uma oportunidade de superação da perspectiva estadocêntrica adotada pelo Direito Internacional Público. in: ARAUJO, Bruno Manoel Viana; SOBRINHO, Liton Lanes Pilau; CARDIN, Valéria Silva Galdino. Direito Internacional III. Florianópolis: CONPEDI, 2016. Disponível em: < https://www.conpedi.org.br/publicaco es/02q8agmu/50b3b67z/0p38hRLfVzN8V8D9.pdf>. Acesso em 24 jul. 2017.

56 FRASER, Nancy. Social Justice in the Age of Identity Politics: redistribution, recognition, and participation. In: FRASER, Nancy; HONNETH, Axel. Redistribution or Recognition? A politicalphilosophical exchange. Londres: Verso, 2003.

57 THORESON, Ryan. R.. Transnational LGBT Activism: Working for Sexual Rights Worldwide. Minneapolis: University of Minnesota Press, 2014, p. 28 ss. foi amplamente impulsionada pela sociedade civil..$^{58}$

Desse modo, constata-se que um dos caminhos para a superação do paradigma do Direito Internacional Monocromático consiste na edição de instrumentos internacionais vinculantes, capazes de fornecer maior segurança jurídica, que prevejam direitos específicos e substantivos aos LGBTIs e cuja elaboração se dê com a participação direta e efetiva desses indivíduos.

\section{Considerações finais}

$\mathrm{O}$ artigo dedicou-se à realização de um estudo acerca da tutela internacional, em nível de legislação e jurisprudência, dos direitos dos LGBTIs.

Como ponto de partida, realizou-se revisão bibliográfica com intuito de expor o marco teórico que conduz o presente estudo, que é a teoria do reconhecimento enquanto status social de Nancy Fraser. Com base nessa chave de leitura e no raciocínio hipotético-dedutivo, questionou-se se a legislação e a jurisprudência internacionais apresentam proteção e reconhecimento suficientes aos indivíduos LGBTIs. Valendo-se do método jurídico-compreensivo da pesquisa, desmembrou-se o problema em diferentes aspectos para melhor análise.

No capítulo dois, foi utilizada análise documental com intuito de apreciar a legislação internacional vigente no que tange à (ausência de) proteção de pessoas LGBTIs. Desse modo, fez-se uma leitura crítica da Carta Internacional de Direitos Humanos (composta pela Declaração Universal dos Direitos Humanos, pelo Pacto Internacional de Direitos Econômicos Sociais e Culturais e pelo Pacto Internacional de Direitos Civis e Políticos), dos diplomas que fundamentam os sistemas regionais de proteção de Direitos Humanos (Europeu, Interamericano e Africano), das Resoluções expedidas pelas Nações Unidas e dos Princípios de Yogyakarta.

Os resultados encontrados pela análise confirmaram a hipótese da insuficiência de reconhecimento e proteção de pessoas LGBTIs na legislação internacional, ou seja, de um Direito Internacional Monocromático. Isso porque os diplomas internacionais com força vinculante são silentes em relação à proteção ou à vedação

58 THORESON, Ryan. R.. Transnational LGBT Activism: Working for Sexual Rights Worldwide. Minneapolis: University of Minnesota Press, 2014, p. 45 
de discriminação de pessoas LGBTIs. Por outro lado, as resoluções da ONU e os Princípios de Yogyakarta tutelam esses indivíduos, mas carecem de normatividade. Sendo assim, a atual proteção LGBTI na legislação internacional somente ocorre pela interpretação ampliativa de dispositivos genéricos nos tratados de Direitos Humanos, o que resulta na falta de segurança jurídica e na ausência do avanço de direitos mais específicos para a dignidade dessas pessoas.

Posteriormente, no terceiro capítulo, passou-se ao exame jurisprudencial de casos relativos à temática LGBTI nas Cortes de Direitos Humanos. A partir da análise de uma amostragem não probabilística, constatou-se que o reconhecimento de direitos a esses indivíduos se dá sempre de forma indireta pelas cortes e com grande primazia de embasamento no direito à privacidade.

Desse modo, o quarto capítulo foi dedicado a uma análise conjunta do paradigma do Direito Internacional Monocromático, a partir dos resultados obtidos nos dois capítulos anteriores. Abordou-se, também, a necessidade de que a alteração do presente paradigma se dê por meio da elaboração de um instrumento internacional vinculante, que forneça reconhecimento e segurança jurídica aos LGBTIs e que conte com seu protagonismo no processo de criação normativa, privilegiando uma perspectiva do Direito Internacional de baixo para cima.

\section{REFERÊNCIAS}

ACCIOLY, Hidelbrando; SILVA, G.E do Nascimento; CASELLA, Paulo Borba.

Manual de Direito Internacional Público. 22.ed. São Paulo: Saraiva, 2016.

ALMEIDA, Bruno Rodrigues de. Os casamentos e as parcerias entre pessoas do mesmo sexo no direito internacional privado brasileiro: aspectos transnacionais das famílias contemporâneas. Revista de Direito Internacional, Brasília, v. 11, n. 1, 2014 p. 43-52. DOI: 10.5102/rdi.v11i1.2832

BORRILLO, Daniel. Homofobia: história e crítica de um preconceito. Belo Horizonte: Autêntica, 2016.

BOURDIEU, Pierre. O Poder Simbólico. Lisboa: Edições 70, 2015.
CANÇADO TRINDADE, Antônio Augusto. Desafios E Conquistas Do Direito Internacional Dos Direitos Humanos No Início Do Século XXI. Disponível em: <https://www.oas.org/dil/esp/407-490\%20cancado $\% 20$ trindade $\% 20$ OEA $\% 20$ CJI $\% 20 \% 20$.def.pdf $>$. Washington: OEA, 2006. Acesso:17 mar. 2017.

CONSELHO DA EUROPA (CE). Convenção Europeia dos Direitos do Homem, 1950. Disponível em: $<$ http://www.echr.coe.int/Documents/Convention_ POR.pdf >. Acesso em: 13 jul. 2017

EUROPA, Corte Europeia de Direitos Humanos. Case of O.M v. Hungary, julgamento em 5 jul. 2016

Case of Taddeucci and McCall v. Italy, julgamento em 20 jun. 2016.

Case of M.C. and A.C v. Romania, julgamento em 12 maio 2016.

Case of Identoba and others v. Georgia, julgamento em 12 maio de 2016.

Case of Oliari and Others v. Italy, julgamento em 21 jul. 2015.

Case of Hämäläinen v. Finland, julgamento em 16 jul. 2014.

Case of M.E v. Sweden, julgamento em 26 jun. 2014.

Case of $\mathbf{X}$ and Others v. Austria, julgamento em 19 fev. 2013.

2012.

Case of $\mathbf{X}$ v. Turkey, julgamento em 9 out.

Case of I. v. The United Kingdom, julgamento em 11 jul. 2012.

Case of Christine Goodwin v. The United Kingdom, julgamento em 11 jul. 2012.

Case of Genderdoc-M v. Moldova, julgamento em 12 jun. 2012.

Case of Gas and Dubois v. France, julgamento em 15 mar. 2012.

Case of Schalk and Kopf v. Austria, julgamento 24 jun. 2010.

Case of L. v. Lithuania, julgamento em 11 set. 2007.

Case of Grant v. The United Kingdom, julgamento em 23 maio 2006. 
Case of B.B.v. The United Kingdom, julgamento em 10 fev. 2004.

Case of Van Kuck v. Germany, julgamento em 12 jun. 2003.

Case of $\mathrm{X}, \mathrm{Y}$ and $\mathrm{Z}$ v. The United Kingdom, julgamento em 22 abr. 1997.

Case of B. v. France, julgamento em 22 mar. 1992.

Case of Cossey v. The United Kingdom, julgamento em 17 set. 1990.

Case of Rees v. The United Kingdom, julgamento em 17 out. 1986.

Case of Van Oosterwijck v. Belgium, julgamento em 6 nov. 1980.

FERREIRA, Gustavo Bussmann. A proteção da orientação sexual e identidade de gênero diversas na corte penal internacional: Entre Realpolitiks E Os Direitos Humanos. Revista de Direito Internacional, Brasília, v. 14 , n. 2, 2017 p. $312-329$

FRASER, Nancy. Heterosexism, Misrecognition, and Capitalism: A Response to Judith Butler. Social Text, Durham, v. 0, n. 52/53, p. 279-289, 1997.

Rethinking Recognition. New Left Review, Londres, n. 3, p. 107-120, maio-jun 2000.

Social Justice in the Age of Identity Politics: redistribution, recognition, and participation. In: FRASER, Nancy; HONNETH, Axel. Redistribution or Recognition? A political-philosophical exchange. Londres: Verso, 2003.

From Redistribution to Recognition? Dilemmas of Justice in a "Postsocialist" Age. In: OLSON, Kevin. Adding Insult to Injury: Nancy Fraser debates her critics. London-New York: Verso, 2008.

Reenquadrando a Justiça em um Mundo Globalizado. Lua Nova, São Paulo, n. 77, p. 11-39, 2009.

GREER, Steven. Europe. In: MOECKLI, Daniel; SHAH, Sangeeta; SIVAKUMARAN, Sandesh. International Human Rights Law. Oxford: Oxford University Press, 2014, p. 416-440.

HEYNS, Christof; KILLANDER, Magnus. Africa. n: MOECKLI, Daniel; SHAH, Sangeeta; SIVAKUMARAN, Sandesh. International Human Rights Law. Oxford: Oxford University Press, 2014, p. 441-457.
JANSEN, Sabine; SPIJKERBOER, Thomas. Fleeing Homophobia: Asylum Claims Related to Sexual Orientation and Gender Identity in the EU. Amsterdam: COC Nederland - Vrije Universiteit Amsterdam, 2011. Disponível em: https://ssrn.com/abstract=2097783

LELIS, Rafael Carrano. Direitos Humanos e Reconhecimento: uma análise da tutela internacional dos direitos LGBTTIs. In: SALLES, Denise et al. Direito Internacional, Comunidade e Relações Internacionais. Rio de Janeiro: Multifoco, 2017.

O'FLAHERTY, Michael. Sexual Orientation and Gender Identity. In: MOECKLI, Daniel; SHAH, Sangeeta; SIVAKUMARAN, Sandesh. International Human Rights Law. Oxford: Oxford University Press, 2014, p. 303-315.

ORGANIZAÇÃO DAS NAÇÕES UNIDAS (ONU). Escritório do Alto Comissariado para os Direitos Humanos. Nascidos Livres e Iguais: orientação sexual e identidade de gênero no regime internacional de direitos humanos. Brasília: UNAIDS, 2013.

Alto Comissariado das Nações Unidas para Direitos Humanos. Tackling Discrimination against Lesbian, Gay, Bi, Trans, \& Intersex People: standards of conduct for business. Nova Iorque, 2017a. Disponível em: <https://www.unfe.org/wp-content/ uploads/2017/09/UN-Standards-of-Conduct.pdf>. Acesso em 15 out. 2017.

ORGANIZAÇÃO DOS ESTADOS AMERICANOS (OEA). Corte Interamericana de Direitos Humanos. Solicitud de Opinión Consultiva OC-24, 2017. Disponível em: <http://www.corteidh.or.cr/docs/asuntos/solicitud_31_03_17.pdf>. Acesso em: 01 jun. 2017.

Corte Interamericana de Direitos Humanos.

Violência Contra Pessoas LGBTI, 2015. Disponível em: <http://www.oas.org/pt/cidh/docs/pdf/ViolenciaPessoasLGBTI.pdf>. Acesso em: 16 jul. 2017.

Corte Interamericana de Direitos Humanos. Case of Atala Riffo and daughters v. Chile. São José, 2012. Disponível em: <http://corteidh.or.cr/docs/ casos/articulos/seriec_239_ing.pdf>. Acesso em: 31 maio 2017.

Corte Interamericana de Direitos Humanos. Opinión Consultiva OC-24/17 De 24 De Noviembre de 2017 Solicitada Por La República De Costa Rica. Disponível em: <http://www.corteidh.or.cr/ 
docs/opiniones/seriea_24_esp.pdf >. Acesso em 3 fev. 2018.

ORGANIZATION OF AFRICA UNITY (OAU). African Commission on Human and Peoples' Rights. 275: Resolution on Protection against Violence and other Human Rights Violations against Persons on the basis of their real or imputed Sexual Orientation or Gender Identity. Luanda: maio 2014. Disponível em: < http:// www.achpr.org/sessions/55th/resolutions/275/>. Acesso em: 03 fev. 2018.

PIOVESAN, Flávia. Temas de Direitos Humanos 6.ed. São Paulo: Saraiva, 2013.

Sistema Interamericano de Direitos Humanos: impacto transformador, diálogos jurisdicionais e os desafios da reforma. Revista de Estudos Constitucionais, Hermenêutica e Teoria do Direito, 6(2), p. 142154, jul-set 2014.

Direitos Humanos e Justiça Internacional: um estudo comparativo dos sistemas regionais europeu, interamericano e africano. São Paulo: Saraiva, 2014.

PUREZA, José Manuel. Defensive and oppositional counter-hegemonic uses of international law: from the International Criminal Court to the common heritage of humankind. in: RODRIGUEZ-GUARAVITO, César A.; SANTOS, Boaventura de Sousa. Law and Globalization from Below: towards a cosmopolitan legality. Cambridge: Cambridge University Press, 2005.

RAMOS, André de Carvalho. Processo Internacional de Direitos Humanos. São Paulo: Saraiva, 2016.

Curso de Direitos Humanos. São Paulo: Saraiva, 2017.

Teoria Geral dos Direitos Humanos na Ordem Internacional. São Paulo: Saraiva, 2017.

RODRIGUEZ-GUARAVITO, César A.; ARENAS, Luis Carlos. Indigenous rights, transnational activism, and legal mobilization: the struggle of the U'wa people in Columbia. in: RODRIGUEZ-GUARAVITO, César A.; SANTOS, Boaventura de Sousa. Law and Globalization from Below: towards a cosmopolitan legality.
Cambridge: Cambridge University Press, 2005.

ROLAND, Manoela Carneiro; ANGELUCCI, Paola Durso. O Processo de Elaboração do Tratado de Direitos Humanos e Empresas: uma oportunidade de superação da perspectiva estadocêntrica adotada pelo Direito Internacional Público. in: ARAUJO, Bruno Manoel Viana; SOBRINHO, Liton Lanes Pilau; CARDIN, Valéria Silva Galdino. Direito Internacional III. Florianópolis: CONPEDI, 2016. Disponível em: < https:/ / www.conpedi.org.br/publicacoes/02q8agmu/50b3b67 z/0p38hRLfVzN8V8D9.pdf>. Acesso em 24 jul. 2017.

SEDGWICK, Eve Kosofsky. A epistemologia do armário. Cad. Pagu, Campinas, n. 28, p. 19-54, June 2007 Disponível em: <http://www.scielo.br/scielo.php? script $=$ sci_arttext $\&$ pid $=$ S0104$83332007000100003 \& \operatorname{lng}=$ en\&nrm $=$ iso $>$. acesso em 10 dez. 2017. http://dx.doi.org/10.1590/S010483332007000100003.

THE YOGYAKARTA PRINCIPLES (YP). Principles on the application of international human rights law in relation to sexual orientation and gender identity, mar. 2007. Disponível em: <http:// www.yogyakartaprinciples.org/wp/wp-content/uploads/2016/08/principles_en.pdf>. Acesso em: 01 jun. 2017.

THE YOGYAKARTA PRINCIPLES PLUS 10 (YP10). Additional principles and state obligations on the application of international human rights law in realtion to sexual orientation, gender identity, gender expression and sex characteristics to complement the Yogyakarta Principles. Geneva: nov. 2017. Disponível em: < http://yogyakartaprinciples.org/wp-content/uploads/2017/11/A5_yogyakartaWEB-2.pdf>. Acesso em: 03 fev. 2018.

THORESON, Ryan. R.. Transnational LGBT Activism: Working for Sexual Rights Worldwide. Minneapolis: University of Minnesota Press, 2014,

VASCONCELOS, Raphael Carvalho de. Constituicionalização e Direito Internacional Privado no Brasil. Rev. secr. Trib. perm. revis. ano 4, mai. 2016, p 185-205. 


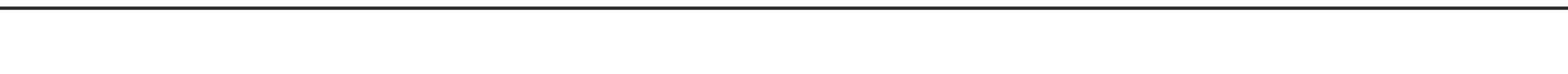




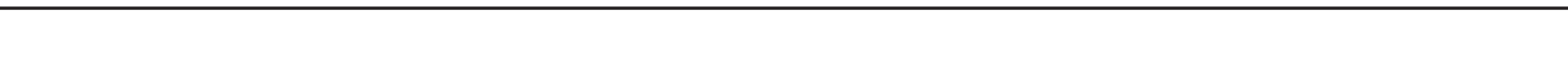


Para publicar na Revista de Direito Internacional, acesse o endereço eletrônico www.rdi.uniceub.br ou www.brazilianjournal.org.

Observe as normas de publicação, para facilitar e agilizar o trabalho de edição. 